\title{
Impact of the Mount Pinatubo eruption on cirrus clouds formed by homogeneous freezing in the ECHAM4 GCM
}

\author{
U. Lohmann \\ Department of Physics and Atmospheric Science, Dalhousie University, Halifax, Nova Scotia, Canada \\ B. Kärcher \\ Deutsches Zentrum für Luft- und Raumfahrt, Institut für Physik der Atmosphäre, Wessling, Germany \\ C. Timmreck \\ Max Planck Institute for Meteorology, Hamburg, Germany
}

Received 18 November 2002; revised 15 March 2003; accepted 25 March 2003; published 17 September 2003.

[1] Volcanic emissions may have the potential to alter cirrus cloud properties. Here we conduct different sensitivity studies with the ECHAM4 general circulation model for 2.5 years after the Mount Pinatubo eruption (July 1991 to December 1993) and compare homogeneous cirrus formation caused by sedimenting sulfate particles produced in the eruption plume with homogeneous cirrus formation in the undisturbed atmosphere. In the first scenario, the sulfate aerosol mass from Pinatubo is added to the background aerosol concentration assuming a monomodal aerosol. Here the aerosol concentration increases by up to $3000 \mathrm{~cm}^{-3}$ in 1992, which can be regarded as an upper limit more representative for the first months after the eruption. The ice crystal number concentration increases by up to $1 \mathrm{~cm}^{-3}$ near the tropical tropopause more than doubling the pre-existing concentration in this region one year after the eruption. In the second, more realistic, scenario the Pinatubo aerosol is added to a bimodal background size distribution as a separate large particle mode. Here the aerosol number concentration increases by $10-25$ $\mathrm{cm}^{-3}$, which can be regarded as a lower bound more representative for what has been observed in 1992. Then the ice crystal number increases at most 50\% in the tropics in 1992. Satellite observations show an increase in ice water path starting in 1992 that could be related to either the Mount Pinatubo eruption or the El Niño event or both but a decrease in total cloud cover. While there is no trend on cloud microphysical or optical properties in our second scenario, the first scenario shows a pronounced increase in ice water path and a noticeable impact on cloud radiative forcing. INDEX TERMS: 0305 Atmospheric Composition and Structure: Aerosols and particles (0345, 4801); 0320 Atmospheric Composition and Structure: Cloud physics and chemistry; 3367 Meteorology and Atmospheric Dynamics: Theoretical modeling; KEYWORDS: cirrus clouds, aerosols, volcanic eruption, Mount Pinatubo

Citation: Lohmann, U., B. Kärcher, and C. Timmreck, Impact of the Mount Pinatubo eruption on cirrus clouds formed by homogeneous freezing in the ECHAM4 GCM, J. Geophys. Res., 108(D18), 4568, doi:10.1029/2002JD003185, 2003.

\section{Introduction}

[2] Cirrus clouds are crucially important to global radiative processes and the thermal balance of the Earth. Cirrus clouds mainly contribute to the cloud greenhouse effect because of their high altitude and their much lower temperature as compared to the underlying surface and their relatively small optical depth. As the optical depth increases, these clouds become opaque to upwelling terrestrial radiation quicker than they become reflective to solar radiation; that is, their greenhouse effect dominates over their albedo effect [e.g., Ackerman et al., 1988]. Numerical predictions of climate change must correctly simulate these

Copyright 2003 by the American Geophysical Union. 0148-0227/03/2002JD003185 clouds and their seasonal and annual variations to properly account for radiometric effects in the Earth's energy budget.

[3] Concerns have been raised about the potential of anthropogenic emissions of aerosols and their precursors to modify cirrus clouds. For instance, aircraft particle emissions (mainly black carbon and sulfate aerosols) may modify cirrus cloudiness [Boucher, 1999; Penner et al., 1999]. New results suggest an impact of contrails on regional scale surface temperatures [Travis et al., 2002]. A related question that needs to be addressed is: How important are indirect effects of volcanic aerosols on cirrus clouds [Robock, 2002]?

[4] Wang et al. [1995] evaluated Stratosphere Aerosol and Gas Experiment (SAGE) data and polar stratospheric clouds sighted by the Stratospheric Aerosol Measurement (SAM) II following the El Chichón eruption in 1982. They 
concluded that volcanic aerosols reduce the cloud effective radius and, in turn, alter the frequency distribution of the cloud extinction coefficient. On the contrary, Wylie and Menzel [1999] analyzed 8 years, from 1989 through 1997, of global cirrus cloud statistics from the High-Resolution Infrared Radiation Sounder (HIRS). They concluded that the HIRS data did not show a real noticeable change in cirrus clouds after the Mount Pinatubo eruption.

[5] Luo et al. [2002] analyzed three satellite-based cirrus data sets produced by International Satellite Cloud Climatology Project (ISCCP), the split-window analysis and the Improved Initialization Inversion. They found that the Mount Pinatubo volcanic aerosol did not have a significant systematic effect on cirrus cloud coverage and brightness temperature difference, which is a surrogate for cloud optical thickness. Therefore they conclude that previous studies that showed some changes must have found isolated local effects and that aerosol-cirrus-radiative interactions do not lead to significant climate feedbacks.

[6] In contrast to these controversial satellite studies, simulations from models of different complexity have suggested an effect of the Pinatubo aerosol on cirrus clouds. Jensen and Toon [1992] used a detailed microphysical model to simulate the volcanic effects on cirrus cloud microphysics. Using homogeneous freezing rates that were state-of-the-art at that time, they concluded that sedimenting volcanic aerosols have the potential to significantly alter the properties of cirrus clouds that form in slow updrafts. They find that after the Mount Pinatubo eruption the ice crystal concentration is increased fivefold compared to unperturbed conditions.

[7] Kärcher and Lohmann [2002b] derived an approximate, physically based parameterization of cirrus cloud formation by homogeneous freezing including the effects of aerosol size. The parameterization is validated using an adiabatic parcel model. Excellent agreement is reached in the fast growth regime, where only a few aerosols are activated. Here the particles rapidly grow to ice crystal size losing the information on their initial size. The fast growth regime is characterized by low updraft velocities and high temperatures. At high vertical velocities and cold temperatures, freezing can occur in sudden bursts activating many aerosols. As the aerosols compete for the available water vapor, they grow slower and do not become as large, leading to a marked dependence on the initial aerosol size. Using this parameterization, Kärcher and Lohmann [2002b] reproduced the Pinatubo calculations by Jensen and Toon [1992] using a parcel model. The newer freezing rates that have become available since then together with new observations showing larger supersaturations with respect to ice than assumed by Jensen and Toon [1992] decrease the effect of volcanic aerosols on ice crystal concentration such that the ice crystal number concentration is only increased by $23 \%$.

[8] Liu and Penner [2002] studied the effect of the sulfate aerosol from Mount Pinatubo on ice nucleation in the upper troposphere using a global chemistry and transport model (CTM). They concluded that large homogeneous ice nucleation rates of the Mount Pinatubo sulfuric acid aerosol are found at the bottom of the aerosol layer during the first year of eruption and therefore the Pinatubo sulfate aerosol could have influenced cirrus formation and evolution globally. However, they used a simplified parameterization of homogeneous ice nucleation that is not linked to a cloud scheme, and therefore they cannot make any statements beyond nucleation rates. As the number of ice crystals that form in a given updraft is not directly governed by the nucleation rate itself [Kärcher and Lohmann, 2002a], a change of the rate by many orders of magnitude does not necessarily result in a dramatic change of the number of ice crystals formed.

[9] In this paper, we introduce the above-mentioned parameterization of homogeneous freezing of supercooled solution droplets including aerosol size effects by Kärcher and Lohmann [2002b] into the ECHAM4 general circulation model (GCM) [Roeckner et al., 1996] to investigate the effect of the Mount Pinatubo eruption on homogeneous cirrus cloud formation on a global scale. Whereas the CTM by Liu and Penner [2002] cannot account for the effects of the Pinatubo aerosol on cirrus clouds, the ECHAM4 GCM solves prognostic equations for the cloud ice mass mixing ratio and ice crystal number concentration. With that we are able to investigate aerosol effects on cirrus cloud microphysical and optical properties. The new parameterization of homogeneous freezing including aerosol size effects and the treatment of aerosols and clouds in ECHAM4 is briefly explained in the next section. Validation with observations is discussed in section 3. To investigate the effect of the Mount Pinatubo eruption on different cirrus cloud properties, different sensitivity simulations following its eruption in June 1991 are evaluated in section 4. Section 5 summarizes the results and concludes this paper.

\section{Model Description and Experimental Design \\ 2.1. Treatment of Aerosols and Clouds in ECHAM4}

[10] The ECHAM4 model used in this study is a modified version based on Lohmann and Kärcher [2002]. Prognostic aerosol variables are mass mixing ratios of sulfate $\left(\mathrm{SO}_{4}\right)$, methane sulfonic acid (MSA), hydrophilic and hydrophobic organic carbon (OC), hydrophilic and hydrophobic black carbon (BC), submicron and supermicron dust $(0-1 \mu \mathrm{m}$ and $1-2 \mu \mathrm{m})$, and submicron and supermicron sea salt $(0-1 \mu \mathrm{m}$ and $1-10 \mu \mathrm{m})$. Transport, dry and wet deposition, and chemical transformations of the aerosols and gaseous precursors are calculated on line with the GCM [Feichter et al., 1996].

[11] The total number of hygroscopic aerosols, $N_{a}$, that is used as the upper bound for the number of homogeneously frozen haze droplets, $N_{i}$, is obtained by assuming an externally mixed aerosol,

$$
N_{a}=N_{\text {seasalt }}+N_{B C}^{p h i l}+N_{O C}^{p h i l}+N_{\text {dust }}+N_{S O_{4}}+N_{M S A} .
$$

We convert the mass of each aerosol component into an aerosol particle number assuming a separate lognormal distribution, density, variance, and a mode radius typical for each species. We use the aerosol densities as described by Hess et al. [1998]. Previously, we also used the aerosol climatology from Hess et al. [1998] for mode radii and variances for each aerosol type. However, we found that it leads to an underestimation of aerosol particles in the upper troposphere [Lohmann and Kärcher, 2002] probably caused by too large aerosol mode radii and too large variances [Lesins and Lohmann, 2003]. Therefore we now assume that the aerosols fall in four size categories, which are represented by lognormal distributions. Mode radii and standard deviations are globally prescribed and change for the two smallest 
size categories with altitude as observed by DeReus et al. [2001] and Schröder et al. [2002]. Carbonaceous aerosols fall into the smallest size class in accordance with the aerosol climatology described by Hess et al. [1998]. They are assumed to have a mode radius increasing from $0.03 \mu \mathrm{m}$ below $4 \mathrm{~km}$ [DeReus et al., 2001] to $0.05 \mu \mathrm{m}$ above $10 \mathrm{~km}$ [Schröder et al., 2002] and a standard deviation between 1.55 and 1.8. Ammonium sulfate, methane sulfonic acid, and submicron seasalt fall into the second smallest category, with a vertically uniform standard deviation of 1.5 and a mode radii decreasing from $0.08 \mu \mathrm{m}$ below $4 \mathrm{~km}$ [DeReus et al., 2001] to $0.05 \mu \mathrm{m}$ above $10 \mathrm{~km}$ [Schröder et al., 2002]. The third size class is the smaller coarse mode with a mode radius of $0.45 \mu \mathrm{m}$ and a standard deviation of 1.5 everywhere. It is assumed to be composed of sea salt and smaller size dust in ECHAM4. The fourth size class is comprised of the larger size dust with a mode radius of $1.9 \mu \mathrm{m}$ and a standard deviation of 2.15 [Hess et al., 1998]. In the experiments described in this study the minimum number of aerosol particles assumed to always be present has been increased from $1 \mathrm{~cm}^{-3}$ to 10 particles $\mathrm{cm}^{-3}$ in better accordance with observations [Minikin et al., 2003].

[12] The prognostic cloud variables are the mass mixing ratios of cloud liquid water and cloud ice and the number concentrations of cloud droplets and ice crystals, as described by Lohmann and Kärcher [2002]. Fractional cloud cover is diagnosed from relative humidity following Sundqvist et al. [1989]. We replaced the autoconversion rate of cloud droplets to form rain drops and the accretion rate of cloud droplets with rain drops by Beheng [1994] with the rates by Khairoutdinov and Kogan [2000] because the dependence of the autoconversion rate on liquid water content in the Khairoutdinov and Kogan [2000] scheme is in better agreement with solving the stochastic collection equation using different observed cloud droplet distributions [Wood, 2002]. We also introduced the improved calculation of the effective longwave cloud fraction and the maximum-random overlap of clouds by Räisänen [1997] in this version.

[13] In the reference simulation HOM, the number of newly frozen ice crystals at temperatures below $-35^{\circ} \mathrm{C}$ is obtained from the parameterization by Kärcher and Lohmann [2002a],

$$
N_{i}=\min \left[\frac{m_{w}}{\rho_{i}}\left(\frac{b_{2}}{2 \pi b_{1}}\right)^{3 / 2} \frac{a_{1} S_{c r}}{a_{2}+a_{3} S_{c r}} \frac{w}{\sqrt{\tau}} ; N_{a}\right]
$$

where $m_{w}$ is the molecular weight of water, $\rho_{i}$ is the ice crystal density $\left(=925 \mathrm{~kg} \mathrm{~m}^{-3}\right), S_{c r}$ is the critical supersaturation where freezing commences, $w$ is the updraft velocity, $\tau \propto 1 / w$ is the characteristic timescale of the nucleation event, and $a_{1}, a_{2}=1 / N_{s i}, a_{3}, b_{1} \propto N_{s i}\left(S_{c r}-1\right)$, and $b_{2}$ are temperature-dependent variables explained by Kärcher and Lohmann [2002a]. Finally, $N_{s i}(T)$ denotes the water vapor number density at ice saturation. Recall that $N_{i}$ is limited by the number of hygroscopic aerosol particles $N_{a}$. Equation (2) does not take the effects of aerosol size on $N_{i}$ into account.

[14] When aerosol size effects are introduced, the freezing/growth term becomes considerably more complicated. Here we only reproduce the number of ice crystals formed by homogeneous freezing assuming a monodisperse aerosol particle size distribution,

$$
N_{i} \propto a_{1} S_{c r} w \frac{N_{s i}(T)}{R_{i, m}\left(r_{0}\right)},
$$

where $R_{i, m}\left(r_{0}\right)$ is the monodisperse freezing/growth integral as explained by Kärcher and Lohmann [2002b] that depends on the initial particle radius $r_{0}$.

[15] The parameterization scheme considers a multimodal aerosol size structure, with an arbitrary number of modes each of which characterized by a lognormal distribution curve. Consequently, the parameterization is called by ECHAM4 with the mean number radius of the freezing particles prior to freezing, along with a total number density and a geometric width for each mode. We consider either a bimodal or trimodal aerosol size distribution as explained in the next subsection.

[16] In the fast growth regime, the number of ice crystals is proportional to the vertical velocity $w^{3 / 2}$ and inversely proportional to temperature via the dependence of saturation vapor pressure over ice on temperature. Here, the number of ice crystals is independent of the initial aerosol size. Aerosol size effects are important in the slow growth regime characterized by high vertical velocities and cold temperatures as discussed by Kärcher and Lohmann [2002b].

[17] In ECHAM4, we obtain the mesoscale updraft velocity $w$ needed for ice crystal formation as the sum of the grid mean vertical velocity and a turbulent contribution expressed in terms of the turbulent kinetic energy (TKE) [Lohmann and Kärcher, 2002],

$$
w=\bar{w}+0.7 \sqrt{T K E} .
$$

While this is a crude approximation to account for subgridscale variability of the vertical wind, this choice of the turbulent contribution in conjunction with the underlying advective transport scheme leads to a reasonable representation of relative humidity in ice-supersaturated regions as shown by Lohmann and Kärcher [2002].

\subsection{Design of the Model Simulations}

[18] The reference simulation HOM and the simulation HOM-Size that includes the parameterization of homogeneous freezing with aerosol size effects [Kärcher and Lohmann, 2002b] were conducted in T30 horizontal resolution with 19 vertical levels and a 30-min time step over a period of 3 years after an initial spin-up of 3 months using climatological sea surface temperatures and sea ice extent.

[19] To investigate the sensitivity of the Mount Pinatubo eruption on cirrus clouds, we performed two sensitivity experiments. In the model an initial volcanic cloud mass of $17 \mathrm{Mt} \mathrm{SO}_{2}$ is assumed and initialized between $0^{\circ} \mathrm{N}-19^{\circ} \mathrm{N}$ and $96^{\circ} \mathrm{E}-118^{\circ} \mathrm{E}$ and between 21.5 and $29 \mathrm{~km}$ according to satellite observations [Timmreck et al., 2003]. The $\mathrm{SO}_{2}$ is added in an ECHAM4 simulation using the ECHAM4 middle atmosphere (MA) version MAECHAM4 [Manzini et al., 1997] employing a bulk aerosol model [Timmreck et $a l ., 2003$ ] and the sulfur cycle described by Feichter et al. [1996]. These MAECHAM4 simulations were performed in $\mathrm{T} 30$ horizontal resolution $\left(3.75^{\circ} \times 3.75^{\circ}\right)$ with 39 levels in 
the vertical from the surface up to $0.01 \mathrm{hPa}$ covering also the upper stratosphere and mesosphere, while the standard ECHAM4 with 19 vertical levels has a model top at $10 \mathrm{hPa}$. The vertical resolution in the upper troposphere in MAECHAM4 with approximately $1.5 \mathrm{~km}$ is slightly smaller than in the standard ECHAM4 (2 km). It is assumed that the volcanic aerosol is log-normally distributed and monomodal, although observations after the Mount Pinatubo eruption [Deshler et al., 1993] report a bimodal volcanic aerosol. This approximation is accurate enough for modes that overlap as compared to other model uncertainties [Russell et al., 1996]. The aerosol size distribution is derived from the aerosol mass and a simple parameterization based on observed correlations between aerosol mass and aerosol surface at Northern Hemisphere midlatitudes according to Grainger et al. [1995] and a constant standard deviation of 1.86 .

[20] The MAECHAM4 results show that the treatment of the volcanic aerosol with a bulk approach and this simple parameterization can reproduce some of the observed atmospheric effects after the Pinatubo eruption. However, unrealistically large radii are calculated at the beginning of the simulation due to the direct relationship between mass and size and the neglect of binary homogeneous nucleation of $\mathrm{H}_{2} \mathrm{SO}_{4} / \mathrm{H}_{2} \mathrm{O}$. As a consequence, the simulated sedimentation rate is too large and leads to an overestimation of the downward transport of the tropical aerosol maximum. Apart from the first 3 months, the simulated aerosol surface area density corresponds well with observations in Northern Hemisphere midlatitudes.

[21] In the first Pinatubo simulation HOM-Pin, we added the monthly mean Pinatubo sulfate aerosol mass from July 1991 to December 1993, as obtained from the difference between a simulation with MAECHAM4 that includes the Pinatubo aerosol as described above and one without [Timmreck et al., 2003], to our background aerosol mass. We applied the sulfate aerosol mode radius and standard deviation used in simulation HOM to obtain the additional number of aerosols. In the simulation HOM-Size we assume a bimodal aerosol, consisting of an accumulation mode and a coarse mode. The accumulation mode aerosol consists of carbonaceous aerosols, sulfate species, and submicron sea salt, i.e., comprises the two smallest size classes mentioned above. The coarse mode corresponds to our third size class consisting of supermicron sea salt and the smaller size dust. The largest size dust hardly reaches the upper troposphere and is therefore neglected for homogeneous freezing. To obtain the mode radii and standard deviations in each aerosol size mode, we weight the mode radius and standard deviation of each log-normally distributed aerosol species by its number concentration. In the second Pinatubo simulation, HOM-Size-Pin, we assume a trimodal aerosol, by directly adding the monthly mean Pinatubo aerosol number concentration and aerosol effective radius from July 1991 to December 1993 from the MAECHAM4 simulations by Timmreck et al. [2003]. Aerosol optical depth is only calculated from the background aerosols.

\section{Comparison With Observations}

[22] We validated the ECHAM4 model including the parameterization of homogeneous freezing without aerosol size effects (simulation HOM) of Lohmann and Kärcher [2002] showing that ECHAM4 captures the observed frequency distribution of supersaturation with respect to ice and cirrus occurrence as a function of large-scale vertical velocity at the Atmospheric Radiation Measurements (ARM) site in Oklahoma. Here we present a few additional validations from simulation HOM.

[23] The validation of relative humidity of Lohmann and Kärcher [2002] used the MOZAIC observations (measurement of ozone on Airbus in-service aircraft) that are mainly obtained over the North American-European flight corridor. Since here we want to study the effect of the tropical volcano eruption Mount Pinatubo in June 1991, we evaluate the simulated relative humidity with respect to ice with different relative humidity measurements in the tropics (within $20^{\circ} \mathrm{S}$ to $20^{\circ} \mathrm{N}$ ) compiled by Folkins et al. [2002]. They found that different instruments, the MLS satellite climatology [Read et al., 2001], the radiosondes released as part of the Southern Hemisphere additional ozonesondes (SHADOZ) project [Thompson et al., 2003] and different aircraft data (E. M. Weinstock and K. K. Kelly, personal communication, 2002), all revealed an increase in relative humidity above $400 \mathrm{hPa}$ as shown in Figure 1. It is attributed mainly to detrainment from convective clouds and may reflect a scarcity in efficient ice nuclei. ECHAM4 is able to capture the first-order effect of increasing relative humidity with height, but is too moist between $250 \mathrm{hPa}$ and $150 \mathrm{hPa}$, indicating that detrainment starts too low.

[24] Mace et al. [2001] studied the frequency of occurrence of ice water content, ice water path, ice crystal size, and number concentration of thin cirrus clouds derived from the 8-mm cloud radar measurements for 1 year of data at the ARM site in Oklahoma. The ECHAM4 data for this comparison are taken from 3 years from the gridpoint closest to the ARM site and are also restricted to optically thin single layer cirrus defined as having an emissivity below 0.85 and not obscured by lower level clouds [Mace et al., 2001]. As shown in Figure 2, the ice water content and ice water path frequency distributions are positively skewed, such that high values of ice water content/path occur less frequently than low values. ECHAM4 reproduces the observed ice water path distribution well but fails to predict high ice water contents. This is an artifact of the coarse vertical resolution of the model. In order to reproduce the correct ice water path, the ice water content has to be smaller than observed because the layers in the upper troposphere are approximately $2 \mathrm{~km}$ thick whereas $50 \%$ of the observed clouds are thinner than $2 \mathrm{~km}$ [Mace et al., 2001]. The ice crystal effective radius and ice crystal number concentration are more uncertain parameters to be derived from the radar measurements (G. G. Mace, personal communication, 2002). Nevertheless, the agreement of the simulated ice crystal size and ice crystal number concentration histograms for thin cirrus with the observed ones is remarkable.

[25] Ström et al. [2002] evaluated aircraft data obtained during the INCA campaign (interhemispheric differences in cirrus properties from anthropogenic emissions) from Prestwick, Scotland, at $53^{\circ} \mathrm{N}$ in October/November 2000 and from Punta Arenas, Chile, at $54^{\circ} \mathrm{S}$ in March/April 2000 to better understand cirrus formation. They presented the vertical velocity as a function of relative humidity with respect to ice and of the number of ice crystals in clouds 


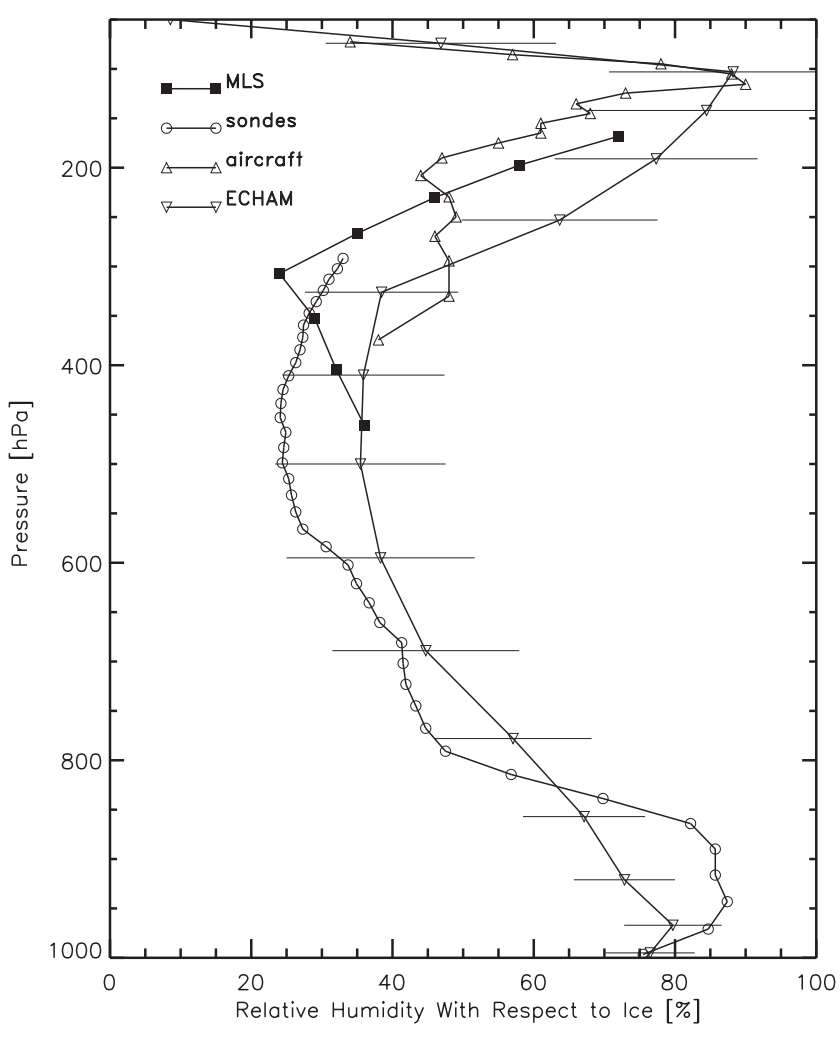

Figure 1. Relative humidity with respect to water for temperatures above $0^{\circ} \mathrm{C}$ and with respect to ice below $0^{\circ} \mathrm{C}$ from observations within $20^{\circ} \mathrm{S}$ to $20^{\circ} \mathrm{N}$ (see text) and from the reference simulation HOM averaged over $20^{\circ} \mathrm{S}$ to $20^{\circ} \mathrm{N}$. Horizontal bars for the ECHAM4 data refer to \pm 1 standard deviation.

above $6 \mathrm{~km}$ and with temperatures below $235 \mathrm{~K}$ as shown in Figure 3. To obtain a similar sample size from ECHAM4, the data for this comparison are taken from the same months as observed from the whole latitude bands between $50^{\circ} \mathrm{N}-$ $57^{\circ} \mathrm{N}$ and $50^{\circ} \mathrm{S}-57^{\circ} \mathrm{S}$ for 2 years and are also restricted to clouds with temperatures below $235 \mathrm{~K}$ above $400 \mathrm{hPa}$.

[26] The envelope of the vertical velocity shows the range of ice crystal concentrations per relative humidity interval. It shows that clouds form during updrafts at the highest relative humidities, hence the highest ice crystal concen-
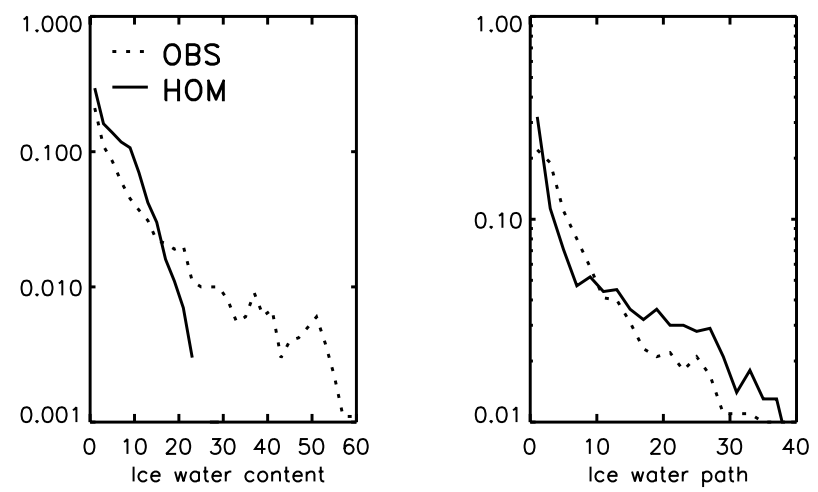

trations. During the life cycle of cirrus clouds ice crystals sediment and aggregate, thus lower ice crystal concentrations occur at lower relative humidities. Below 100\% relative humidity, dominated by downdrafts, the ice crystals start to sublimate. As the vertical velocity increases, more ice crystals will freeze homogeneously as discussed by Kärcher and Lohmann [2002a], which contributes to the increase of ice crystal number with increasing relative humidity. The patterns are comparable for clouds in both hemispheres.

[27] We present the comparison both for the large-scale (grid-mean) vertical velocity and the mesoscale vertical velocity used for ice crystal formation (equation (4)). The grid-mean vertical velocity is lower than observed because of the large grid size, but it reflects the underlying largescale dynamics. As our vertical velocity for cloud formation is obtained from the turbulent kinetic energy, it cannot follow the relative humidity distribution as closely as the grid-mean vertical velocity. Therefore the mesoscale vertical velocity does not vary with relative humidity above $110 \%$. As $\mathrm{N}_{i}$ depends strongly on vertical velocity (equation (2)), this comparison stimulates improvements as to how best to obtain a vertical velocity representative for cloud formation in future work.

[28] In summary, ECHAM4 reproduces the main properties of thin cirrus clouds at the ARM site and the tropical relative humidity distribution. It also captures the distribution of vertical velocity as a function of ice crystal concentration and relative humidity with respect to ice. Therefore we feel confident to now investigate the impact of the Pinatubo aerosol on cirrus clouds.

\section{Sensitivity Studies}

\subsection{Zonal Mean and Geographical Distributions}

[29] The trimodal aerosol of the simulation HOM-SizePin is shown in Figure 4 averaged over the year following the Mount Pinatubo eruption, corresponding to the Pinatubo aerosol of 1992. Recall that only the sulfate aerosol is representative of 1992, but we used climatological sea surface temperature to isolate the effect of the volcanic aerosol. The accumulation mode aerosol is characterized by aerosol numbers exceeding $100 \mathrm{~cm}^{-3}$ below $330 \mathrm{hPa}$ decreasing to between 10 and $20 \mathrm{~cm}^{-3}$ above $200 \mathrm{hPa}$ with mode radii between $0.0375 \mu \mathrm{m}$ and $0.05 \mu \mathrm{m}$. The coarse

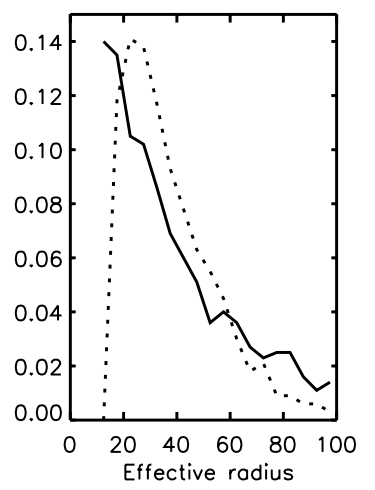

Figure 2. Frequency of occurrence of ice water content $\left(\mathrm{mg} \mathrm{m}^{-3}\right)$, ice water path $\left(\mathrm{g} \mathrm{m}^{-2}\right)$, effective ice crystal radius $(\mu \mathrm{m})$, and ice crystal number concentration $\left(\mathrm{L}^{-1}\right)$ from radar data (dotted lines) and from the reference simulation HOM (solid line). 

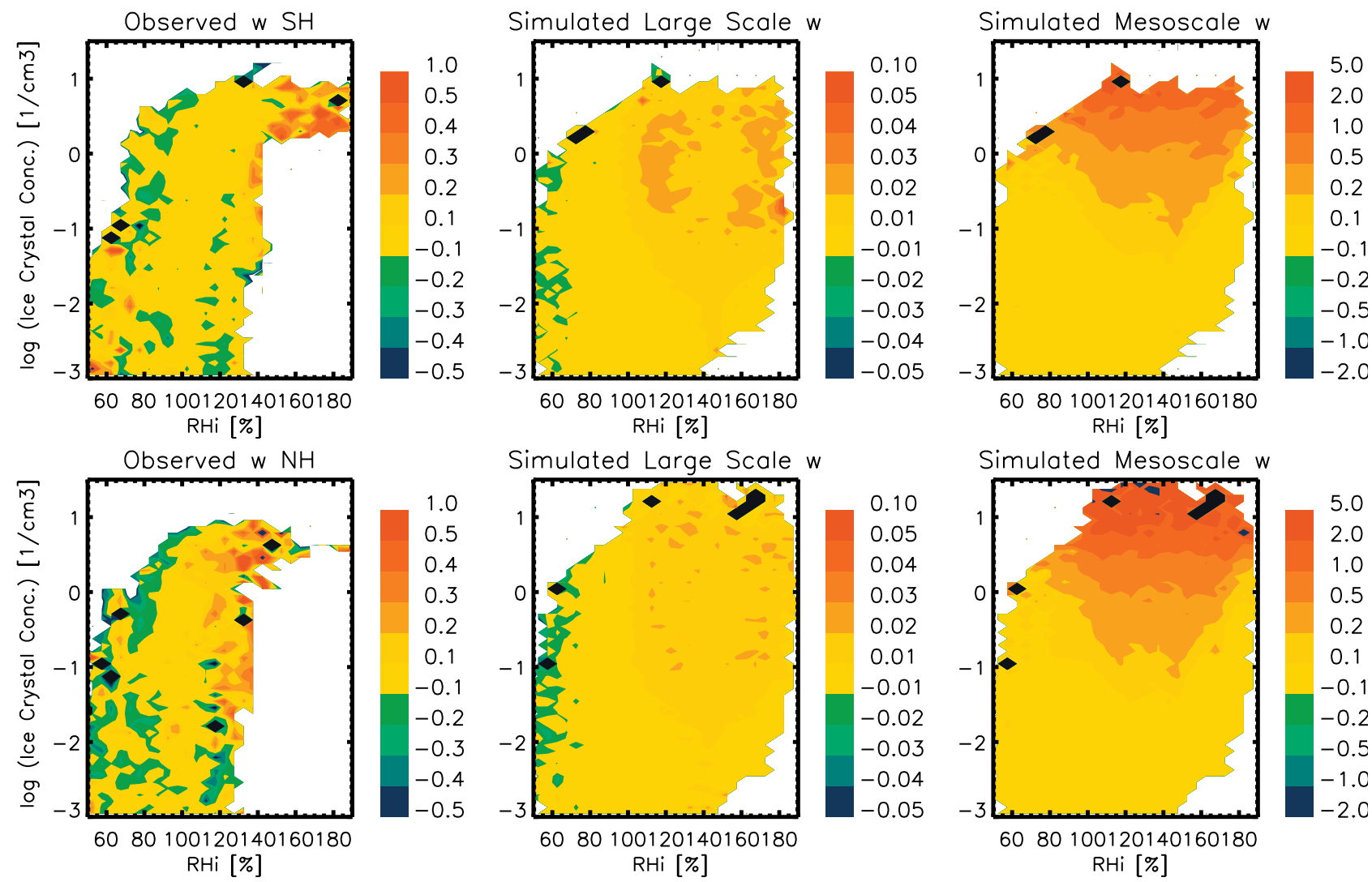

Figure 3. Vertical velocity $\left(\mathrm{m} \mathrm{s}^{-1}\right)$ as a function of ice crystal number concentration and relative humidity with respect to ice (RHi) from observations and from the reference simulation HOM for Southern Hemisphere data (upper row) and Northern Hemisphere data (lower row) as adapted from Ström et al. [2002]. Vertical velocity from HOM is divided into large-scale vertical velocity and mesoscale vertical velocity used for homogeneous freezing (equation (4)).

mode aerosol number concentration is below $0.2 \mathrm{~cm}^{-3}$ everywhere with a constant mode radius of $0.45 \mu \mathrm{m}$ (not shown). The Mount Pinatubo eruption adds between 10 and 25 particles $\mathrm{cm}^{-3}$ with mode radii of $0.075 \mu \mathrm{m}$ to $0.3 \mu \mathrm{m}$ in accordance with observations by Deshler et al. [1993].

[30] Figure 5 shows the aerosol number concentration from the simulations HOM and the differences, HOM-Pin HOM, HOM-Size - HOM, and HOM-Size-Pin - HOMSize averaged over the year following the Mount Pinatubo eruption. The aerosol number increases by more than 3000 particles $\mathrm{cm}^{-3}$ in high latitudes and high altitudes in the first scenario where the Pinatubo aerosol mass is added to the background aerosol and the background aerosol mode radius is used to calculate the additional aerosol number concentration. This increase is reduced to the observed increase in aerosol particle concentration between 10 and $30 \mathrm{~cm}^{-3}$ in the second scenario where the Pinatubo aerosol number concentration is directly added. The increase in aerosol number concentration in HOM-Pin is much larger than in HOM-Size-Pin because our background aerosol mode radius is $0.05 \mu \mathrm{m}$ above 200 $\mathrm{hPa}$ whereas the mode radius of the Pinatubo aerosol exceeds $0.15 \mu \mathrm{m}$ in high latitudes and altitudes (see Figure 4).

[31] As a result of the applied parameterization to obtain the aerosol size distribution of the Pinatubo aerosol based on correlations between aerosol mass and aerosol surface in
MAECHAM4 [Timmreck et al., 2003], the Pinatubo aerosol radius is overestimated in the first months after the eruption, which leads to a larger than observed sedimentation rate of the aerosol particles and an overestimation of the downward transport in the tropics where the bulk of the aerosol is bound. Furthermore the aerosol number concentration is underestimated in the first months after the eruption in the MAECHAM4 simulations [Timmreck et al., 2003]. Shortly after the Pinatubo eruption, new particles formed through binary homogeneous nucleation, leading to a strong increase in aerosol number. In the first weeks after the eruption of Mount Pinatubo an increase of several hundred particles $\mathrm{cm}^{-3}$ was found in the concentration of condensation nuclei in the volcanic layers [Deshler et al., 1992]. After the El Chichón eruption the observed increase in the aerosol number was even 1 order of magnitude larger (2500 particles $\mathrm{cm}^{-3}$ ) [Wilson et al., 1983]. Thus HOM-Pin could be regarded as an upper limit more representative for the first months after the eruption and the more realistic scenario HOM-Size-Pin as a lower limit more representative for 1992.

[32] The increase in aerosol number concentration is more pronounced at high latitudes rather than at the equator because, in addition to the overestimated sedimentation rate in the tropics, the meridional poleward transport is overestimated in the model. This leads to a shift of the tropical maximum to higher northern latitudes 3 months earlier than observed [Timmreck et al., 1999]. Smaller changes in 


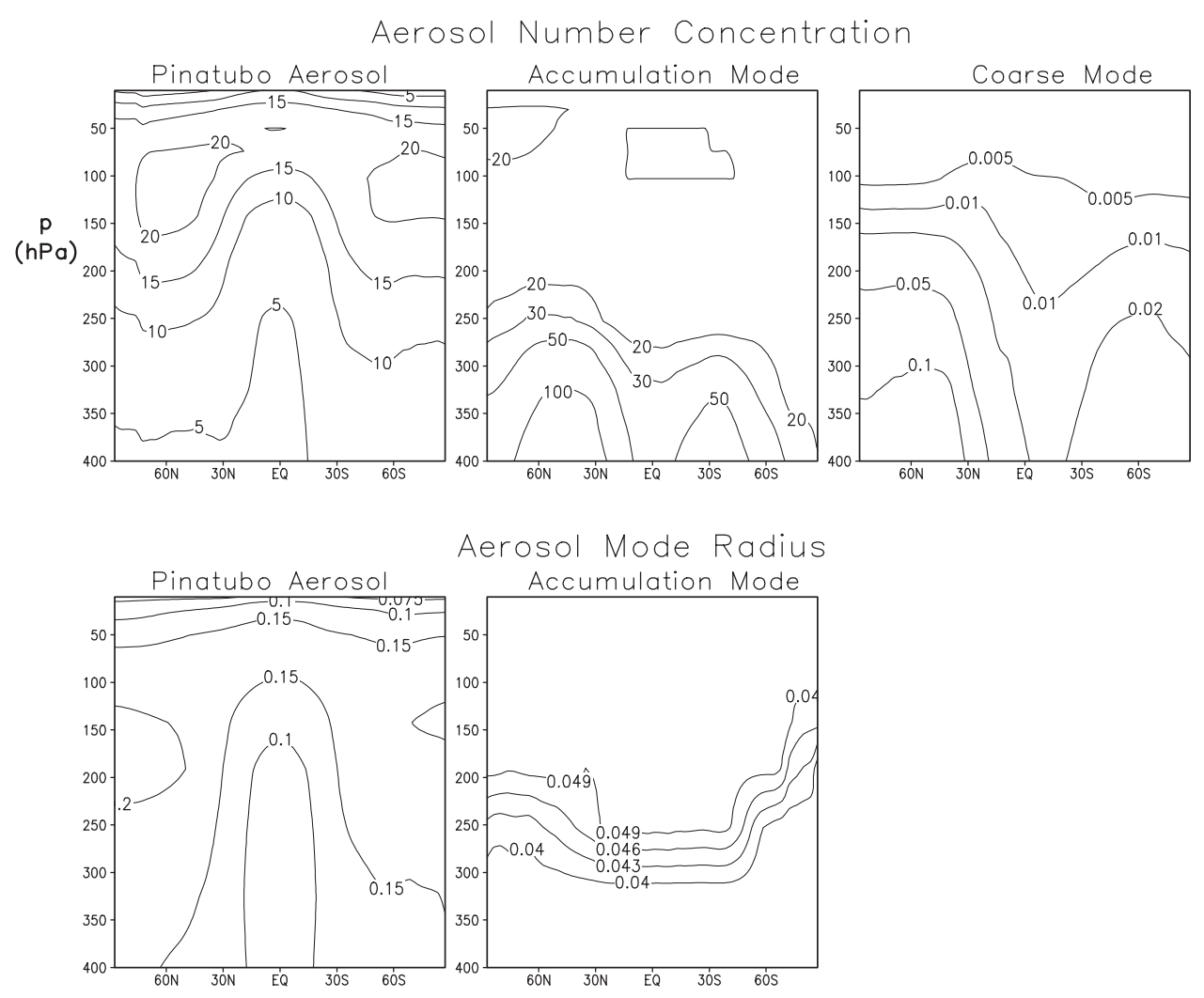

Figure 4. Annual zonal mean latitude versus pressure cross sections of aerosol number concentration $\left(\mathrm{cm}^{-3}\right)$ and mode radii $(\mu \mathrm{m})$ for the trimodal aerosol averaged over the year after the Mount Pinatubo eruption.

aerosol number concentration between the different simulations, especially in the lower troposphere, are a result from slight changes in the dynamics between these different simulations.

[33] The ice crystal number concentration increases up to $0.5 \mathrm{~cm}^{-3}$ in the zonal mean in HOM-Size as compared to HOM, which corresponds to a twofold increase at most. It suggests that these regions are slow growing regimes, which are characterized by high vertical velocities and cold temperatures, in which aerosol size effects are important for homogeneous freezing. The ice crystal concentration is up to $1 \mathrm{~cm}^{-3}$ higher in the zonal mean in HOM-Pin as compared to HOM indicating that the ice crystal number concentration in HOM is limited by the number of hygroscopic aerosols present. This increase is most significant between 300 and $450 \mathrm{hPa}$ in the tropics where the ice crystal number concentration is more than a factor of 10 higher than in the reference simulation HOM. The increase in ice crystal concentration, which can be attributed to the increase in aerosol number concentration from the volcanic eruption, remains below 50\% if HOM-Size-Pin is compared to HOMSize.

[34] The Pinatubo aerosol impact on the cloud ice mixing ratio is less pronounced as on ice crystal number concentration. While the global annual mean change in ice water path between HOM-Size and HOM and between HOM-Size-Pin and HOM-Size is below $0.1 \mathrm{~g} \mathrm{~m}^{-2}$, the ice water path in HOM-Pin is increased by $0.4 \mathrm{~g} \mathrm{~m}^{-2}$ in the year after the Pinatubo eruption as compared to
HOM. In this scenario, the cloud ice mixing ratio increases up to $100 \%$ between 500 and $300 \mathrm{hPa}$ and slightly decreases aloft (see Figure 5).

\subsection{Temporal Evolution}

[35] Figure 6 shows the temporal evolution of the global mean aerosol and ice crystal number concentration for 2.5 years starting from July 1991. There is an annual variation in aerosol number concentration with a maximum in summer and minimum in winter reflecting the higher dust and sea salt emissions in summer. As already seen in Figure 5, the aerosol number concentration hardly changes between the simulations HOM-Size and HOM, but increases in both Pinatubo simulations. The large increase in aerosol number concentration in HOM-Pin is caused by assuming a monomodal aerosol as discussed above. The maximum increase in aerosol number concentration occurs within 12 months after the eruption above $100 \mathrm{hPa}$ and takes 6 months to reach the troposphere, where its effect is most noticeable in 1992. The aerosol number concentration decreases again in 1993. Owing to the applied parameterization of Timmreck et al. [2003], the simulated aerosol number maximum is correlated with the maximum volcanic load in contrast to the observation where maximum number concentrations are found within the first 2 months.

[36] The effect on ice crystal number concentration takes place in the entire upper troposphere between 100 and $500 \mathrm{hPa}$ in the first Pinatubo simulation. Here the increase in ice crystal number due to Pinatubo reaches its maximum 


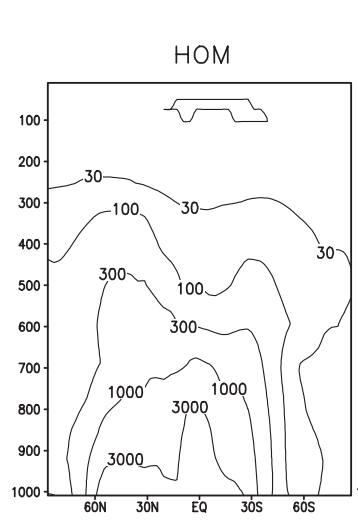

Aerosol Number Concentration

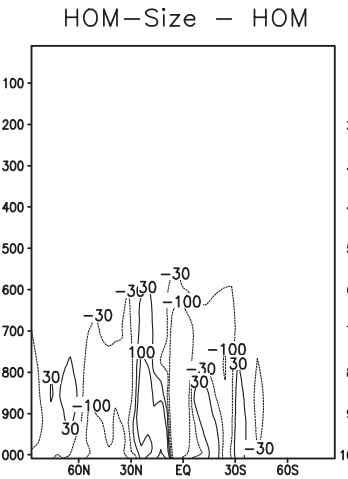

HOM-Pin - HOM HOM-Size-Pin - HOM-Size
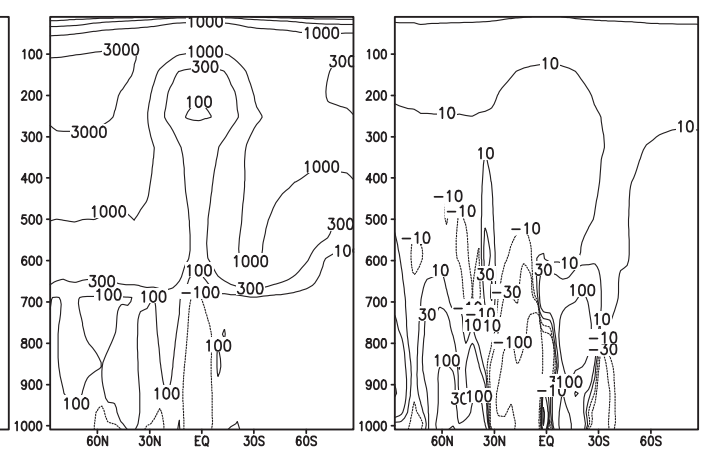

Ice Crystal Number Concentration

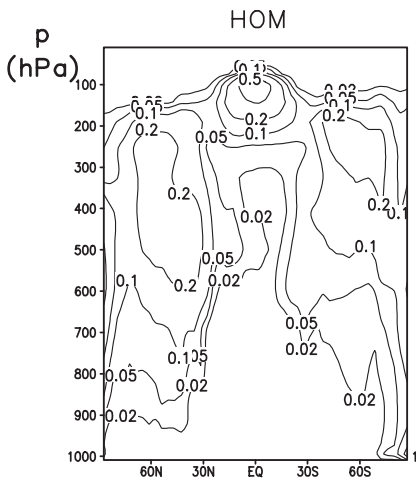

HOM-Size - HOM

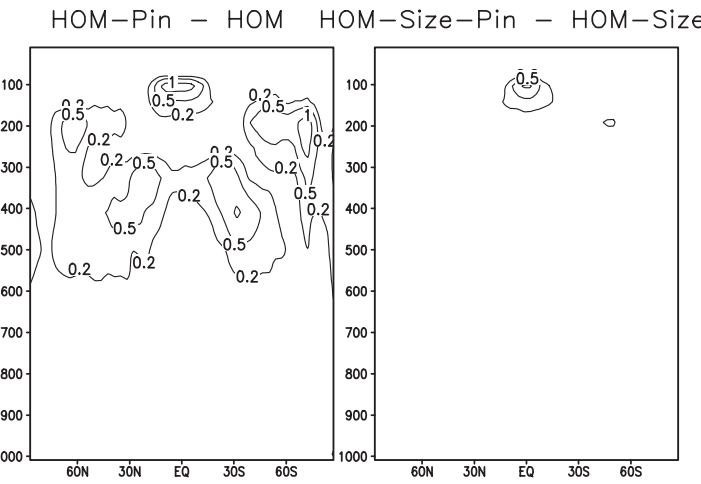

Ice Water Mixing Ratio

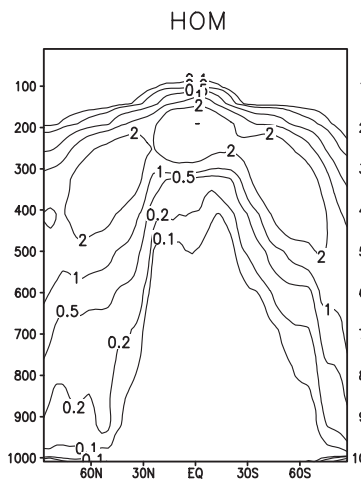

HOM-Size - HOM

HOM-Pin - HOM HOM-Size-Pin - HOM-Siz€

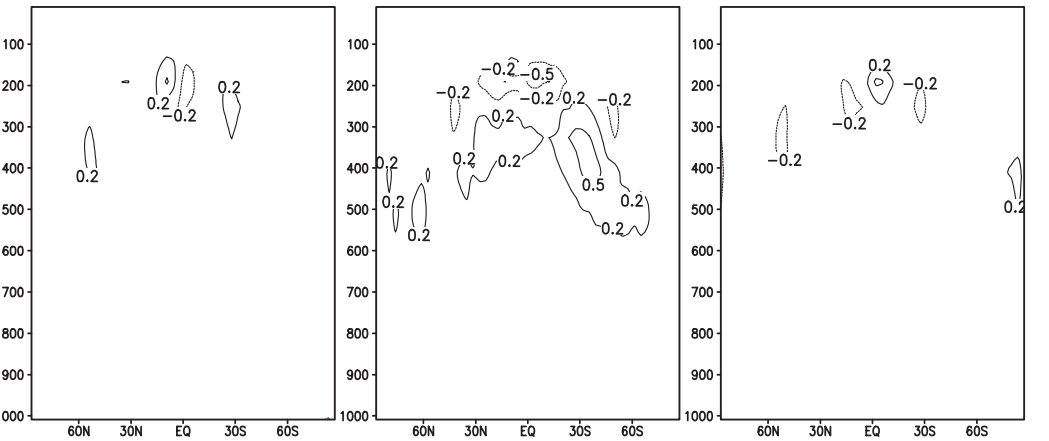

Figure 5. Annual zonal mean latitude versus pressure cross sections of aerosol and ice crystal number concentrations $\left(\mathrm{cm}^{-3}\right)$ and ice water mixing ratio $\left(\mathrm{mg} \mathrm{kg}^{-1}\right)$ averaged over the year after the Mount Pinatubo eruption for the simulations HOM and the differences HOM-Size - HOM, HOM-Pin - HOM and HOM-Size-Pin - HOM-Size.

12 months after the eruption between 350 and $400 \mathrm{hPa}$ with concentrations up to $0.5 \mathrm{~cm}^{-3}$ higher. In the second scenario, the effect on ice crystal concentration is weaker and limited to altitudes between 75 and $175 \mathrm{hPa}$. Here the increase in concentration remains below $0.3 \mathrm{~cm}^{-3}$.

[37] The impact of the Pinatubo aerosol on total and high cloud cover and on ice and liquid water path in the tropics, averaged over $30^{\circ} \mathrm{S}$ to $30^{\circ} \mathrm{N}$, is shown in Figure 7. Time series of anomalies of these quantities are also obtained from various satellite products. Long time series of cirrus clouds are available from the ISCCP [Rossow and Schiffer, 1999]. The new ISCCP-D2 data set has more than 18 years of cloud statistics from July 1983 to August 2001. In this data set the global mean cloud cover has slightly increased from the ISCCP-C data set by reducing biases in cirrus detection sensitivity over land and in cirrus cloud properties. ISCCP data are available for high cloud cover, total cloud cover, and ice and liquid water path. Anomalies are taken as compared to the 18 -year average from July 1983 to June 2001 . The ISCCP ice water path is derived from the total water path when the cloud top temperature is below $233 \mathrm{~K}$ to isolate cirrus clouds. Clouds are taken to be liquid when the cloud top temperature exceeds $263 \mathrm{~K}$. The SAGE satellite observations detect more high clouds than ISCCP because ISCCP cannot detect cirrus clouds with optical depths $<0.1$ [Liao et al., 1995], where SAGE is especially sensitive [Wang et al., 1996]. SAGE data 


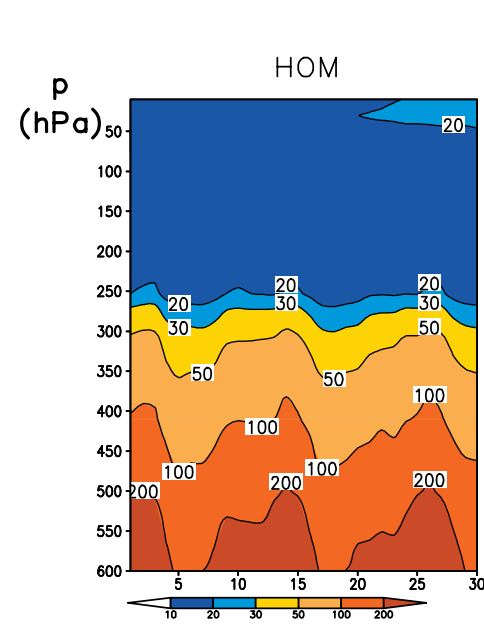

\section{Aerosol Number Concentration}

HOM-Size - HOM

HOM-Pin - HOM HOM-Size-Pin - HOM-Size

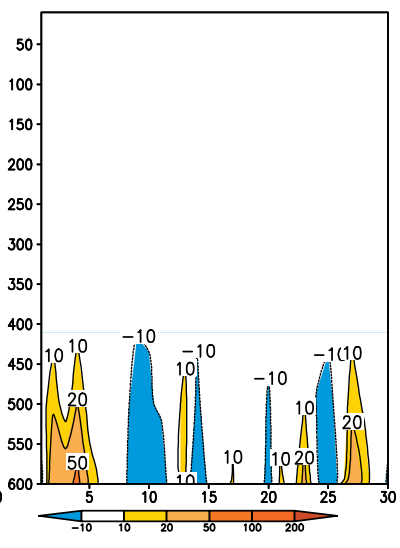

Ice Crystal Number
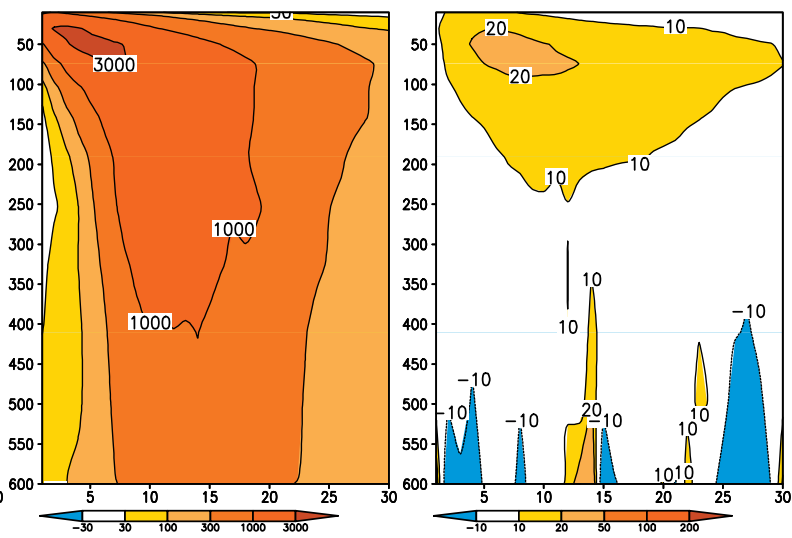

HOM HOM-Size - HOM

\section{Concentration}
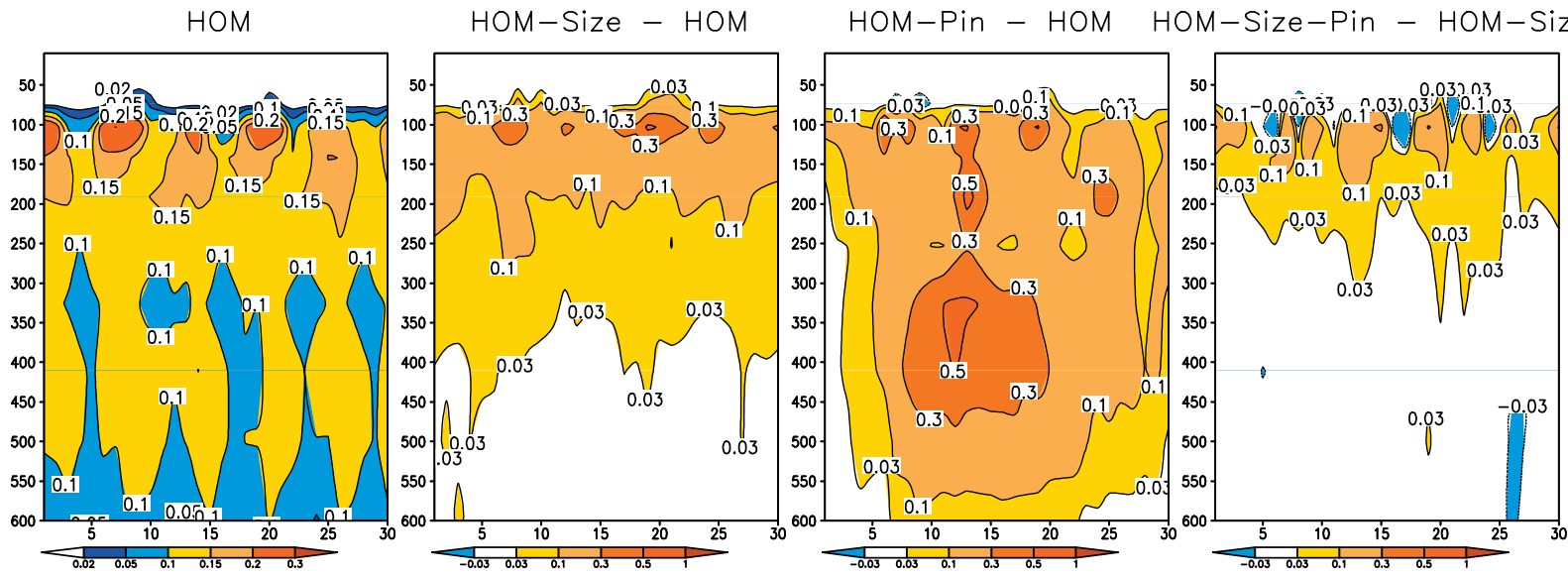

Figure 6. Hovmoeller diagrams of global monthly mean versus pressure cross sections of aerosol and ice crystal number concentrations $\left(\mathrm{cm}^{-3}\right)$ for the simulations HOM and the differences HOM-Size HOM, HOM - HOM-Pin and HOM-Size-Pin - HOM-Size.

of high cloud cover span the 17-year period from 1984 to 2000. Special Sensor Microwave/Imager (SSM/I) data [Ferraro et al., 1996] of liquid water path are available from 1987 to 1998 . However, there are no data for December 1987 and from July 1990 to December 1991 due to instrument failure. Thus monthly mean anomalies are with respect to this 10 - to 11-year period.

[38] ISCCP shows an upward trend in ice water path and high cloud cover starting in late 1992 and continuing in 1993 together with a decrease in total cloud cover over this full 2.5-year period, but a recent study [Luo et al., 2002] indicates that the change in high cloud cover as seen by ISCCP is probably an artifact caused by aerosol contamination. The decrease in total cloud amount goes hand in hand with an increase in outgoing longwave radiation [Chen et al., 2002]. The origin of these changes, however, is not understood yet, as it is not captured by GCM simulations [Wielicki et al., 2002]. No discernible trend is obvious in the SAGE data time series of high cloud cover.

[39] The liquid water path from ISCCP shows a downward trend starting in the beginning of 1993 whereas $\mathrm{SSM} / \mathrm{I}$ shows a decrease in liquid water path starting already in 1992. If the Pinatubo aerosol had an effect on the liquid water path, it should be an increased liquid water path caused by the second indirect aerosol effect. This refers to an increase in cloud lifetime and cloud water content due to the higher aerosol concentrations which result in more and smaller cloud droplets that will not grow to precipitation size as easily, [e.g., Lohmann and Lesins, 2002]. Hence the SSM/I trend may rather be associated with the El Niño-Southern Oscillation (ENSO) event or is a result of the global cooling and drying after the Mount Pinatubo eruption [Soden et al., 2002]. Therefore we conclude that the impact of the volcanic aerosol is limited to cirrus clouds.

[40] The larger impact on ice crystal number concentration in the first scenario than in second scenario is reflected in the increase in ice water path from HOM to HOM-Pin in 1992 whereas the differences HOM-Size-Pin - HOM-Size and HOM-Size - HOM show no trend. The trend in ice water path in the first scenario precedes the observed trend, probably because of the Pinatubo aerosol sedimenting too fast and being transported away from the tropics too quickly as discussed above. As in the observation, there is no noticeable increase in liquid water path. Neither total cloud cover nor high cloud cover vary systematically over the 2.5-year period because the impact on ice water path is not strong enough to cause a significant change in the dynamics 

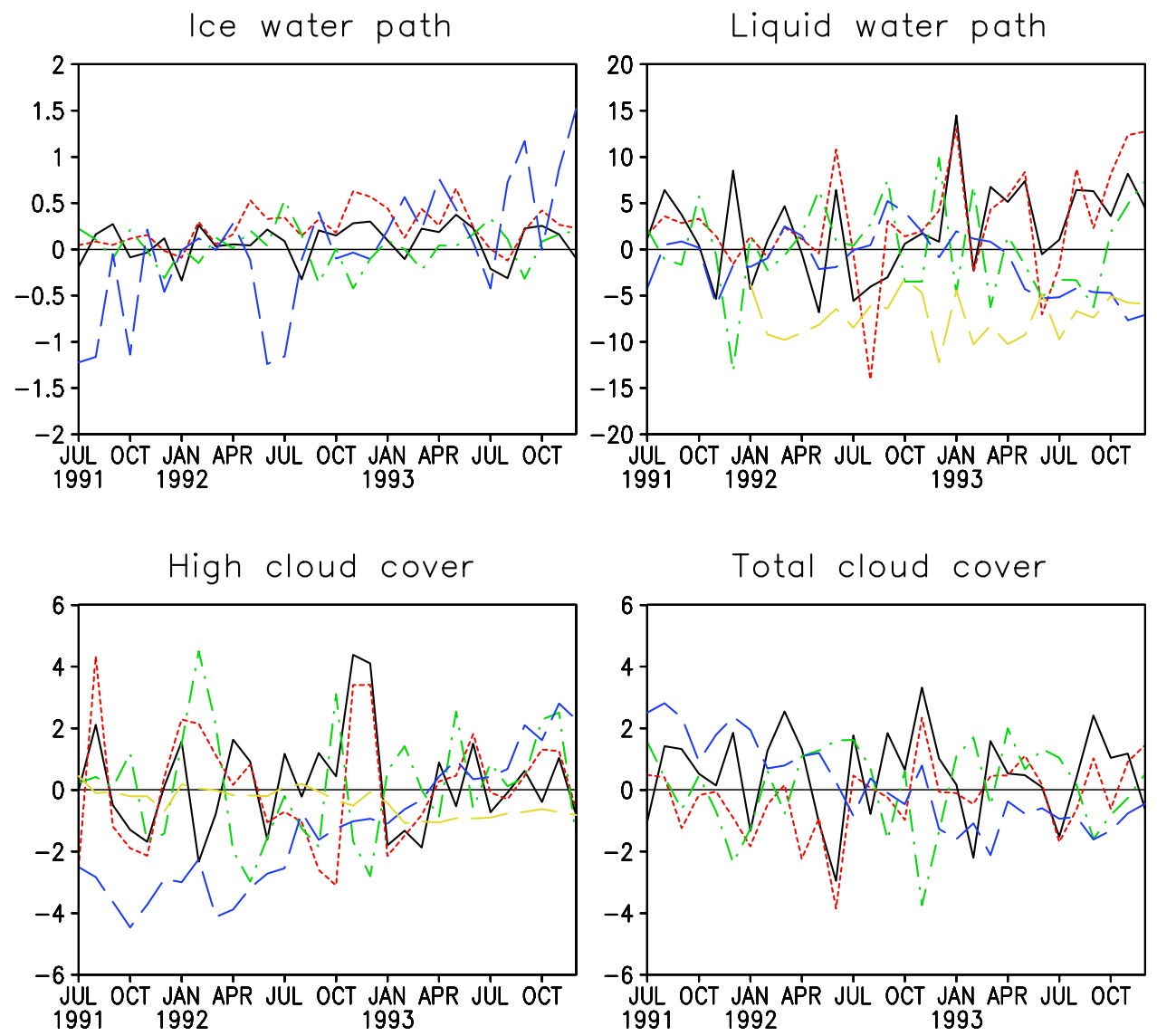

Figure 7. Time series of tropical monthly mean $\left(30^{\circ} \mathrm{S}-30^{\circ} \mathrm{N}\right)$ of ice and liquid water path $\left(\mathrm{g} \mathrm{m}^{-2}\right)$ and high and total cloud cover (\%) for the differences between simulations HOM-Size - HOM (solid black line), HOM-Pin - HOM (dotted red line) and HOM-Size-Pin - HOM-Size (dash-dotted green line) and various observations: anomalies of ice and liquid water path, high and total cloud cover from ISCCP (long dashed blue line), high cloud cover from SAGE (long dashed yellow line), and liquid water path from SSM/I (long dashed yellow line). Note that the ice water path anomalies from ISCCP and the high cloud cover anomalies from SAGE are multiplied by 0.1 to be able to show them on the same scale: that is, they appear a factor of 10 smaller than actually observed.
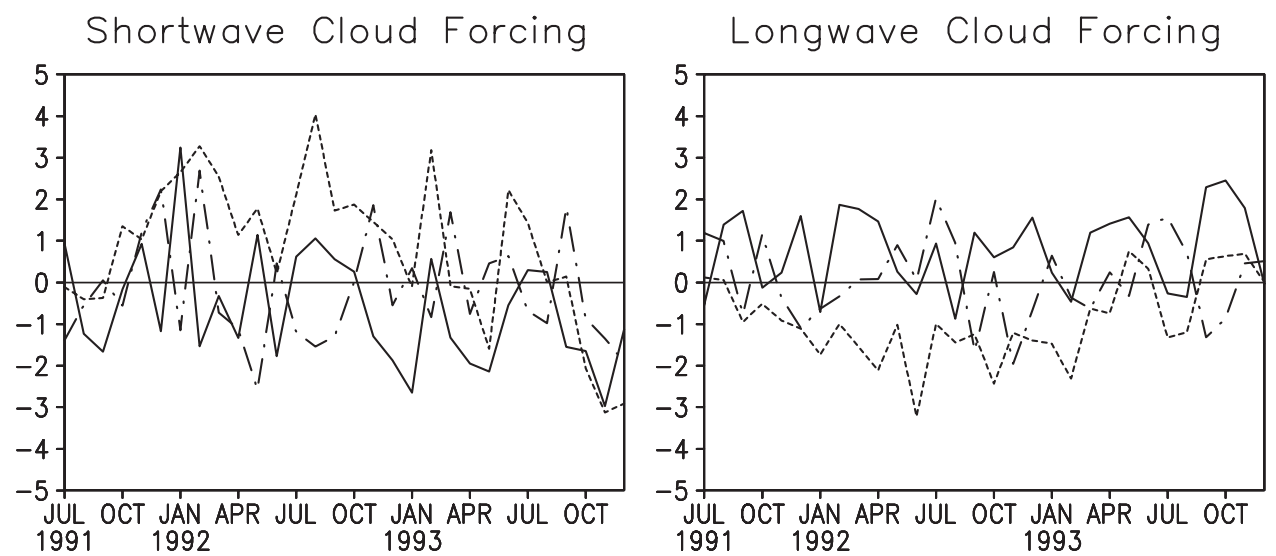

Figure 8. Same as Figure 7 but for shortwave and longwave cloud radiative forcing $\left(\mathrm{W} \mathrm{m}^{-2}\right)$ for the difference between simulations HOM-Size - HOM (solid line), HOM-Pin - HOM (dotted line) and HOM-Size-Pin - HOM-Size (dash-dotted line). 
which, in turn, could alter the relative humidity distribution. This is the only way to affect cloud cover in ECHAM4 as mentioned in section 2.1. As these simulations were performed with climatological sea surface temperature, we cannot reproduce the observed change in dynamics associated with the 1992 El Niño event, which may be responsible for the decrease in total cloud cover.

[41] The impact of the Mount Pinatubo aerosol on the longwave and shortwave cloud radiative forcing in the tropics is shown in Figure 8. The cloud radiative forcing is defined as the difference in the radiative flux at the top of the atmosphere between the cloudy and cloud-free atmosphere. Introducing aerosol size effects increases the longwave cloud radiative forcing averaged over the tropics by $0.8 \mathrm{~W} \mathrm{~m}^{-2}$ and enhances the shortwave cloud radiative forcing by $0.6 \mathrm{~W} \mathrm{~m}^{-2}$ averaged over the 2.5 -year period. It is caused by the increased reflectivity of the more numerous ice crystals in HOM-Size. The changes between HOM-Pin and HOM are in the opposite direction, such that the longwave cloud radiative forcing is reduced by $0.9 \mathrm{~W} \mathrm{~m}^{-2}$ and the shortwave cloud radiative forcing is $0.8 \mathrm{~W} \mathrm{~m}^{-2}$ smaller. The liquid and ice water paths both increase slightly in HOM-Size and in HOM-Pin as compared to HOM over this entire period in the tropics. This by itself would increase the cloud radiative forcings as seen in the difference HOM-Size - HOM. The reduction in longwave cloud radiative forcing in HOM-Pin as compared to HOM is caused by the displacement of ice clouds to lower altitudes (see Figure 5) and the slight overall reduction in total cloud cover in the tropics (see Figure 8), which both act to trap less longwave radiation, thus decreasing the longwave cloud radiative forcing. At the same time, more shortwave radiation is absorbed in the system, decreasing the shortwave cloud radiative forcing. The differences in cloud radiative forcings in scenario 2 between HOM-Size-Pin and HOM-Size remain below $0.3 \mathrm{~W} \mathrm{~m}^{-2}$ and show no trend. These results from this more realistic second scenario of the effect of the Mount Pinatubo eruption on cirrus clouds agree with the findings by Luo et al. [2002].

\section{Summary and Outlook}

[42] We investigated the impact of the Mount Pinatubo aerosol on ice clouds using the ECHAM4 GCM for two different scenarios. In the first scenario we added the sulfate aerosol mass obtained from a bulk aerosol simulation with MAECHAM4 to our background aerosol mass assuming a monomodal aerosol. In the second more realistic scenario, we assumed that the Pinatubo aerosol adds a third mode to the bimodal background aerosol by using the Pinatubo aerosol number concentration and median radius obtained from the MAECHAM4 simulations. The increase in aerosol number concentration in the first scenario exceeds the observed increase after the Mount Pinatubo eruption by 1 order of magnitude, but is in line with aerosol number concentration increases in the first 2 months after the El Chichón outbreak. Therefore this scenario can be regarded as an upper bound more representative for the first months after the eruption. In the second scenario, which can be regarded as a lower bound more representative for 1992, the volcano adds $10-25$ particles $\mathrm{cm}^{-3}$, in agreement with observations of particle concentrations after the Mount
Pinatubo eruption in 1992. This large discrepancy in aerosol concentration in 1992 between both scenarios shows that simplified assumptions about the aerosol size distribution as in the first scenario can have adverse consequences and points to the importance of using accurate size information of aerosols for such comparisons.

[43] The impact on ice crystal number concentration is much smaller, mainly because homogeneous freezing is not limited by the aerosol number concentration most of the time and because homogeneous freezing is rather insensitive to the number and size of aerosol particles present. The main increase in ice crystal number in the second scenario occurs in the tropics between 100 and $200 \mathrm{hPa}$ in the year after the Mount Pinatubo eruption and increases the ice crystal number concentration by at most $50 \%$ or $0.5 \mathrm{~cm}^{-3}$ as compared to the tenfold increase between 300 and $450 \mathrm{hPa}$ in the first scenario.

[44] We also compared the impact of the Mount Pinatubo aerosol on quantities derived from satellites, such as ice and liquid water path and total and high cloud cover. The ISCCP data show an increase in ice water path starting in late 1992. ECHAM4 only simulates an increase in ice water path in the first scenario, which drastically overestimates the observed aerosol number concentration in 1992. The increase even in this scenario occurs earlier than observed, starting at the beginning of 1992. It is probably caused by the higher than observed sedimentation rate of the Pinatubo aerosol from the stratosphere into the cirrus layers.

[45] In agreement with the satellite data analysis following the Mount Pinatubo eruption by Luo et al. [2002], the Pinatubo aerosol has no effect on cloud radiative effects in the second scenario. However, it cannot be ruled out that large increases in aerosol number concentrations from tropical volcanic eruptions, such as found after the El Chichón eruption by Wilson et al. [1983] and for which our first scenario is representative, emit enough aerosols and aerosol precursors in the atmosphere to have a noticeable effect on cloud optical properties.

[46] Massie et al. [2003] found that the frequency of subvisible cirrus and the magnitude of cirrus extinction near the tropopause as analyzed from SAGE II and Halogen Occultation Experiment (HALOE) satellite data decreased after the Mount Pinatubo eruption. The cirrus extinction decreased by $30 \%$ in qualitative agreement with the $10-$ $15 \%$ decrease in cirrus frequency after the El Chichón eruption. Because of the coarse vertical resolution near the tropopause in our model, we could not evaluate changes of subvisible cirrus in our model simulation. Also, subvisible cirrus are likely to be influenced by heterogeneous freezing processes [Kärcher, 2002], for which a parameterization scheme for use in ECHAM4 is not yet available.

[47] One shortcoming of our simulations is that we used climatological sea surface temperature whereas in reality the Mount Pinatubo eruption was followed by a strong ENSO event shortly afterwards. We nevertheless chose to conduct these simulations with climatological sea surface temperature to isolate the effect of volcanic eruptions on cirrus clouds. In order to investigate the combined effects of Mount Pinatubo and ENSO on cirrus clouds and its potential feedback on climate, coupled atmosphere-ocean simulations need to be carried out. They are beyond the scope of this paper, but should be conducted in future. 
[48] We also ignored aerosol radiative feedbacks and the input of water vapor from the volcano in our Pinatubo simulations. Temperature effects were rather small in the upper tropical troposphere between 100 and $300 \mathrm{hPa}$ [Angell, 1997]. Soden et al. [2002] showed that although the global mean lower tropospheric temperature showed a peak cooling of $0.5 \mathrm{~K}$ nearly 18 months after the eruption, the effect on the $6.7 \mu \mathrm{m}$ brightness temperature was small. Pitari and Mancini [2002] found differences in circulation patterns such that the downward flux at the tropopause in middle and high latitudes was increased. These secondary effects may be important as well and should be analyzed in future studies.

[49] While we concentrated only on cirrus cloud formation by homogeneous freezing in this study, heterogeneous freezing might contribute to the formation of cirrus clouds under certain atmospheric conditions [DeMott, 2002]. Especially in the Northern Hemisphere, anthropogenic emissions could lead to cirrus formation by heterogeneous freezing. Here one probably needs to compare homogeneous freezing caused by sulfuric acid from the volcanic eruption with heterogeneous freezing of the background atmosphere. In addition to that, in the first few months after a volcanic eruption, the atmosphere contains ash particles in addition to sulfur species and these could act as heterogeneous ice nuclei. However, given the lack of observations and the different modes of heterogeneous freezing, it is more difficult to develop a parameterization that includes heterogeneous freezing, but this should be accounted for in future work.

[50] Acknowledgments. We thank J. Ström for providing the INCA data, J. Marshall for help with the ISCCP and SAGE data, and G. Lesins for help with the SSM/I data. The SAGE data themselves were made available by NASA-LaRC and NASA Langley Radiation and Aerosols Branch. Observed relative humidity data were provided by I. Folkins and originally obtained through the SHADOZ radiosonde database archived by J. C. Witte and from aircraft data obtained by E. M. Weinstock and K. K. Kelly. U. Lohmann is grateful for support from the Modelling of Global Chemistry for Climate programme (GCC) funded by the National Science and Engineering Research Council of Canada and the Canadian Foundation for Climate and Atmospheric Science. She also thanks the Deutsches Klimarechenzentrum for computing time. Claudia Timmreck is grateful for support from the Bundesministerium für Bildung, Wissenschaft, Forschung und Technologie (BMBF) grant 07ATF43 (project KODYACS) and from the European Commission grant EVK2-CT-2001-000112 (project PARTS). This work contributes to the HGF/BMBF project "Particles and Cirrus Clouds" (PAZI).

\section{References}

Ackerman, T. P., K. N. Liou, F. P. J. Valero, and L. Pfister, Heating rates in tropical anvils, J. Atmos. Sci., 45, 1606-1623, 1988.

Angell, J. K., Stratospheric warming due to Agung, El Chichón and Pinatubo taking into account the quasi-biennial oscillation, J. Geophys. Res., 102, 9479-9485, 1997.

Beheng, K. D., A parameterization of warm cloud microphysical conversion processes, Atmos. Res., 33, 193-206, 1994.

Boucher, O., Air traffic may increase cirrus cloudiness, Nature, 397, $30-$ 31, 1999.

Chen, J., B. E. Carlson, and A. D. Del Genio, Evidence for strengthening of the tropical general circulation in the 1990s, Science, 295, 838-841, 2002.

DeMott, P. J., Laboratory studies of cirrus cloud processes, in Cirrus, edited by D. K. Lynch et al., pp. 102-135, Oxford Univ. Press, New York, 2002.

DeReus, M., R. Krejci, J. Williams, H. Fischer, and R. Scheele, Vertical and horizontal distributions of the aerosol number concentration and size distribution over the northern Indian Ocean, J. Geophys. Res., 106, 28,629-28,641, 2001.

Deshler, T., D. J. Hofmann, B. J. Johnson, and W. R. Rozier, Balloonborne measurements of the Pinatubo aerosol size distribution and volatility at
Laramie, Wyoming during the summer of 1991, Geophys. Res. Lett., 19, 199-202, 1992.

Deshler, T., B. J. Johnson, and W. R. Rozier, Balloonborne measurements of Pinatubo aerosol during 1991 and 1992 at $41^{\circ} \mathrm{N}$ : Vertical profiles, size distribution, and volatility, Geophys. Res. Lett., 20, 1435-1438, 1993.

Feichter, J., E. Kjellström, H. Rodhe, F. Dentener, J. Lelieveld, and G.-J. Roelofs, Simulation of the tropospheric sulfur cycle in a global climate model, Atmos. Environ., 30, 1693-1707, 1996.

Ferraro, R., F. Weng, N. Grody, and A. Basist, An eight year (1987-1994) time series of rainfall, clouds, water vapor, snow-cover, and sea-ice derived from SSM/I measurements, Bull. Am. Meteorol. Soc., 77, 891-905, 1996.

Folkins, I., K. K. Kelly, and E. M. Weinstock, A simple explanation for the increase in relative humidity between 11 and $14 \mathrm{~km}$ in the tropics, J. Geophys. Res., 107, 4736, doi:10.1029/2002JD002185, 2002.

Grainger, R. G., A. Lambert, C. D. Rodgers, F. W. Taylor, and T. Deshler, Stratospheric aerosol effective radius, surface area and volume estimated from infrared measurements, J. Geophys. Res., 100, 16,507-16,518, 1995.

Hess, M., P. Koepke, and I. Schult, Optical properties of aerosols and clouds: The software package OPAC, Bull. Am. Meteorol. Soc., 79, $831-844,1998$

Jensen, E. J., and O. B. Toon, The potential effects of volcanic aerosols on cirrus cloud microphysics, Geophys. Res. Lett., 19, 1759-1762, 1992.

Kärcher, B., Properties of subvisible cirrus clouds formed by homogeneous freezing, Atmos. Chem. Phys., 2, 161-170, 2002.

Kärcher, B., and U. Lohmann, A parameterization of cirrus cloud formation: Homogeneous freezing of supercooled aerosols, J. Geophys. Res., 107, 4010, 10.1029/2001JD000470, 2002a.

Kärcher, B., and U. Lohmann, A parameterization of cirrus cloud formation: Homogeneous freezing including effects of aerosol size, J. Geophys. Res., 107, 4698, 10.1029/2001JD001429, 2002b.

Khairoutdinov, M., and Y. Kogan, A new cloud physics parameterization in a large-eddy simulation model of marine stratocumulus, Mon. Weather Rev., 128, 229-243, 2000.

Lesins, G., and U. Lohmann, GCM aerosol radiative effects using geographically varying aerosol sizes deduced from AERONET measurements, J. Atmos. Sci, in press, 2003.

Liao, X., W. B. Rossow, and D. Rind, Comparison between SAGE II and ISCCP high-level clouds: 1. Global and zonal mean cloud amounts, J. Geophys. Res., 100, 1121-1135, 1995.

Liu, X., and J. E. Penner, Effect of Mount Pinatubo $\mathrm{H}_{2} \mathrm{SO}_{4} / \mathrm{H}_{2} \mathrm{O}$ aerosol on ice nucleation in the upper troposphere using a global chemistry and transport model, J. Geophys., 107, 10.1029/2001JD000455, 2002.

Lohmann, U., and B. Kärcher, First interactive simulations of cirrus clouds formed by homogeneous freezing in the ECHAM GCM, J. Geophys. Res., 107, 4141, 10.1029/2001JD000767, 2002.

Lohmann, U., and G. Lesins, Stronger constraints on the anthropogenic indirect aerosol effect, Science, 298, 1012-1016, 2002.

Luo, Z., W. B. Rossow, T. Inoue, and C. J. Stubenrauch, Did the eruption of the Mt. Pinatubo volcano affect cirrus properties?, J. Clim., 15, 28062820, 2002.

Mace, G. G., E. E. Clothiaux, and T. P. Ackerman, The composite characteristics of cirrus clouds: Bulk properties revealed by one year of continuous cloud radar data, J. Clim., 14, 2185-2203, 2001.

Manzini, E., N. A. McFarlane, and C. McLandress, Impact of the Doppler spread parameterization on the simulation of the middle atmosphere circulation using the MA/ECHAM4 general circulation model, J. Geophys. Res., 102, 25,751-25,762, 1997.

Massie, S., W. Randel, F. Wu, D. Baumgardner, and M. Hervig, Halogen and Occultation Experiment and Stratospheric Aerosol and Gas II observations of tropopause cirrus and aerosol during the 1990s, J. Geophys. Res., 108, 4222, doi:10.1029/2002JD002662, 2003.

Minikin, A., A. Petzold, J. Ström, R. Krejci, M. Seifert, H. Schlager, P. van Velthoven, and U. Schumann, Aircraft observations of the upper tropospheric fine particle aerosol in the Northern and Southern Hemispheres at midlatitudes, Geophys. Res. Lett., 30, 1503, doi:10.1029/2002GL016458, 2003.

Penner, J. E., D. H. Lister, D. J. Griggs, D. J. Dokken, and M. McFarland (Eds.), Aviation and the Global Atmosphere: Intergovernmental Panel on Climate Change, 373 pp., Cambridge Univ. Press, New York, 1999.

Pitari, G., and E. Mancini, Short-term climatic impact of the 1991 volcanic eruption of Mt. Pinatubo and effects on atmospheric tracers, Nat. Hazards Earth Syst. Sci., 2, 91-108, 2002.

Räisänen, P., Effective longwave cloud fraction and maximum-random overlap of clouds: A problem and a solution, Mon. Weather Rev., 126, 3336-3340, 1997.

Read, W. G., J. W. Waters, D. L. Wu, E. M. Stone, and Z. Shippony, UARS Microwave Limb Sounder upper tropospheric humidity measurement: Method and validation, J. Geophys. Res., 106, 32,207-32,258, 2001. 
Robock, A., Blowin' in the wind: Research priorities for climate effects of volcanic eruptions, Eos Trans. AGU, 83, 472, 2002.

Roeckner, E., et al., The atmospheric general circulation model ECHAM4: Model description and simulation of the present day climate, Tech. Rep. 218, Max-Planck-Inst. für Meteorol., Hamburg, Germany, 1996.

Rossow, W. B., and R. A. Schiffer, Advances in understanding clouds from ISCCP, Bull. Am. Meteorol. Soc., 80, 2261-2287, 1999.

Russell, P. B., et al., Global to microscale evolution of the Pinatubo volcanic aerosol derived from diverse measurements and analyses, J. Geophys. Res., 101, 18,745-18,763, 1996.

Schröder, F. P., B. Kärcher, M. Fiebig, and A. Petzold, Aerosol states in the free troposphere at northern midlatitudes, J. Geophys. Res., 107, 8126, 10.1029/2000JD000194, 2002.

Soden, B. J., R. T. Wetherald, G. L. Stenchikov, and A. Robock, Global cooling after the eruption of Mount Pinatubo: A test of climate feedback by water vapor, Science, 296, 727-730, 2002.

Ström, J., M. Seifert, R. Krejci, A. Minikin, A. Petzold, J.-F. Gayet, F. Auriol, J. Ovarlez, and U. Schumann, A statistical approach to a Lagrangian perspective of cirrus evolution based on data from the INCA experiments in the Northern and Southern Hemisphere midlatitudes, paper presented at 11th AMS Conference on Cloud Physics, Am. Meteorol. Soc., Odgen, Utah, June 2-6, 2002.

Sundqvist, H., E. Berge, and J. E. Kristiansson, Condensation and cloud parameterization studies with a mesoscale numerical weather prediction model, Mon. Weather Rev., 117, 1641-1657, 1989.

Thompson, A. M., et al., The 1998-2000 SHADOZ (Southern Hemisphere Additional Ozonesondes) tropical ozone climatology: Comparisons with TOMS and ground-based measurements, J. Geophys. Res., 108, 8238, doi:10.1029/2001JD000967, 2003.

Timmreck, C., H.-F. Graf, and I. Kirchner, A one and a half year interactive simulation of Mt. Pinatubo aerosol, J. Geophys. Res., 104, 9337-9360, 1999
Timmreck, C., H.-F. Graf, and B. Steil, Aerosol chemistry interactions after the Mt. Pinatubo eruption, in AGU Monograph Series, edited by A. Robock and C. Oppenheimer, in press, 2003.

Travis, D. J., A. M. Carleton, and R. G. Lauritsen, Contrails reduce daily temperature range, Nature, 418, 601, 2002.

Wang, P.-H., P. Minnis, and G. K. Yue, Extinction coefficient $(1 \mu \mathrm{m})$ properties of high-altitude clouds from solar occultation measurements (1985-1990): Evidence for volcanic aerosol effect, J. Geophys. Res., 100, 3181-3199, 1995.

Wang, P.-H., P. Minnis, M. P. McCormick, G. S. Kent, and K. M. Skeens, A 6-year climatology of cloud occurrence frequency from Stratospheric Aerosol and Gas Experiment II observations (1985-1990), J. Geophys. Res., 101, 29,407-29,429, 1996.

Wielicki, B. A., et al., Evidence for large decadal variability in the tropical mean radiative energy budget, Science, 295, 841-844, 2002.

Wilson, J. C., E. D. Blackshear, and J. H. Hyun, Changes in the sub-2.5 micron diameter aerosol observed at $20 \mathrm{~km}$ altitude after the eruption of El Chichón, Geophys. Res. Lett., 10, 1029-1032, 1983.

Wood, R., Drizzle in stratocumulus: Observations and model results, paper presented at 11th AMS Conference on Cloud Physics, Am. Meteorol. Soc., Ogden, Utah, 2002.

Wylie, D. P., and W. P. Menzel, Eight years of high cloud statistics using HIRS, J. Clim., 12, 170-184, 1999.

B. Kärcher, DLR Institut für Physik der Atmosphäre, D-82234 Wessling, Germany. (bernd.kaercher@dlr.de)

U. Lohmann, Department of Physics and Atmospheric Science, Dalhousie University, Halifax, Nova Scotia, B3H 3J5, Canada. (Ulrike. Lohmann@Dal.Ca)

C. Timmreck, Max Planck Institute for Meteorology, Bundesstrasse 55, D-20146 Hamburg, Germany. (timmreck@dkrz.de) 